Session 2793

\title{
Using Model Rocketry to Introduce Students to Aerospace Engineering
}

\author{
Eugene E. Niemi, Jr. \\ Mechanical Engineering Department \\ University of Massachusetts Lowell \\ Lowell, MA 01854
}

\begin{abstract}
This paper summarizes five years of experiences with a mini-design module intended to develop the interest of freshmen in aerospace engineering as a career. Model rocketry was one of several modules that students participated in during the course Introduction to Engineering: Design, taught at the University of Massachusetts Lowell. The students were given a project based on designing a reconnaissance rocket to accomplish a certain mission, as outlined below.
\end{abstract}

The rocket had to be designed to rise vertically as high as possible (within constraints) to take wide-angle photos of military emplacements in surrounding countries. The rocket had to deploy a parachute system to return it safely back to earth. It had to have a short total time of flight to minimize exposure time to enemy fire trying to destroy the rocket. This was especially important during the descent phase when the rocket would be moving slowly.

The students had to build a small model rocket from a commercially available kit, make appropriate engine choices, and modify a parachute recovery system and other rocket features to achieve the somewhat conflicting objectives of high altitude and short time of flight. The course procedures, including lectures on dynamics and fluid mechanics appropriate to the freshman level are described, together with experiences gained during the rocket launches. Several clever ideas that the students developed to achieve the desired objectives are described in the paper. Approximately twenty-five students participated each year.

Classroom evaluations conducted with the students at the end of the course each year showed that the students' interest in aerospace and mechanical engineering was heightened as a result of the rocketry module.

\section{Introduction}

A perennial problem facing engineering educators is how to maintain the freshmen students' interest in engineering during the time they are taking basic science, mathematics, and humanities courses. This is compounded by the fact that the students' knowledge of science and mathematics is too basic to present much engineering information at a meaningful level. Most schools attempt to maintain this interest by offering Introduction to Engineering courses, with

Proceedings of the 2002 American Society for Engineering Education Annual Conference \& Exposition

Copyright () 2002, American Society for Engineering Education 
varying degrees of success. Examples of various types of freshman courses can be found in Refs. 1 through 13. Even Introduction to Engineering courses often emphasize topics that are presented in a dry fashion to students, emphasizing such topics as how to study, computer usage, technical writing, etc. What are needed are project-type courses that excite the students and give them an overview of what an interesting engineering project can be. This paper describes such a project that has been used at the University of Massachusetts Lowell for five years, and, based on student evaluations of the course, has been found extremely motivating for the students.

\section{Freshman course format}

The College of Engineering has experimented with different types of freshman engineering courses and has at the current time settled into a somewhat traditional sequence of a two-credit Introduction to Engineering course covering mostly computers the first semester and a two-credit Introduction to Engineering Design the second semester. What has been effective in this second semester is the inclusion of some interesting design modules, especially a rocket design project. The rocketry module is offered at a point in the program where it can build on some basic science and mathematics.

- It builds on basic science and mathematics offered up to this point

- It outlines some more advanced engineering and science that will be offered at a later level, thus piquing the student's interest in learning the new engineering concepts

- It teaches students the concept of how "assumptions" are used to idealize a real problem to make it mathematically manageable

- It allows some hands-on "build-fly" work so the student can be exposed to real hardware

- It provides an opportunity for early "design" work and decision-making at a very fundamental level

Student evaluation data shows that most of these objectives were achieved in a module that the students found to be generally exciting. The instilling of student excitement over their coursework is felt to be vital in maintaining real interest in future studies.

\section{Implementation of the module}

The rocketry module was the last one of three or four freshman modules offered during the second semester. Offering this module at the end of the second semester had two decided advantages: First, most of the students had sufficient time to be exposed to the concepts of impulse and momentum in physics and vacuum trajectory calculations in calculus and physics. Second, it made good weather more likely for the model rocket launches - an important consideration for colleges in the northeastern United States. The class met for one-hour lectures each week and a two-hour lab each week. During the first lecture, the "problem" was posed to the students in the following form:

The armies of the surrounding countries are continually invading your country, "Attackistan," deep in southeastern Europe. Your company manufactures sounding rockets, normally used to study the upper atmosphere. The poor national economy and competition from countries afar, have put your company, "Aeroflop," in deep economic

Proceedings of the 2002 American Society for Engineering Education Annual Conference \& Exposition

Copyright () 2002, American Society for Engineering Education 
distress. A design project has been presented to your company that will give you a chance to rise to national prominence if the project is successful.

You are asked to design a reconnaissance rocket with the following characteristics:

1. It must rise near vertically as high as possible to take wide-angle photos of the military emplacements in the surrounding countries.

2. It must deploy a parachute system to return the rocket with camera equipment to earth safely, although telemetry on board will send some data back even if the rocket cannot be recovered. Parachute recovery is required because the economic base of Attackistan relies significantly on its textile industry. Making the recovery device a parachute will generate internal procurement of significant amounts of parachute material, which will also help boost the national economy.

3. It must have a short total time of flight to minimize exposure time to enemy fire trying to destroy the rocket. This is especially important during the descent phase when the vehicle is moving slowly.

4. The engineering work must be well documented in a technical report so that, if necessary, a later group of engineers can make improvements in the design for future flights.

5. The company's chief engineer, "Herr Dr. Niemi," will examine the quality of your workmanship before flight. This will affect your pay raise in the next salary review cycle. He will also examine the rocket after flight for any damage that might be caused by too rapid a descent.

\section{Logistics}

The logistics of the project were conducted as follows: During the first week, the students were given a lecture describing the project in general, its objectives as outlined above, the schedule, etc. The type of rocket assigned was a commercially available model rocket kit called an Alpha rocket. The specifications for the model are given in Table 1.

Table 1. Alpha rocket specifications

\begin{tabular}{|c|c|}
\hline Length & $31.1 \mathrm{~cm}(12.25 \mathrm{in})$ \\
\hline Diameter & $24.8 \mathrm{~mm}(0.976 \mathrm{in})$ \\
\hline Fins & Three fins (Y arrangement) \\
\hline Material & Plastic, balsa, and cardboard \\
\hline Mass & 22.6 gm (less engine) \\
\hline Engines & $1 / 2 \mathrm{~A} 6-2, \mathrm{~A} 8-3$, or B4-4 \\
\hline
\end{tabular}

The students were told to procure the rocket and have it constructed and ready for firing in two weeks (the time required to build the rocket is on the order of two hours, excluding the painting). Engine choices and parachute modifications were to be started a week later. The second week, the students were given simplified lectures on impulse and momentum, and

Proceedings of the 2002 American Society for Engineering Education Annual Conference \& Exposition

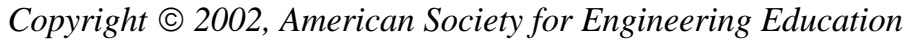


altitude reached by a projectile in a vacuum. They were also taught how to calculate terminal velocity and descent time for a parachute, and given working curves generated by computer solutions to estimate altitude gained by a model rocket for various engine choices, weight, and including the effect of air resistance. They were also given suggestions on possible parachute modifications to increase rate of descent. They were asked to select a rocket engine within certain constraints, modify their parachute if desired, and bring it in for weighing and preflight inspection a few days before launch.

The following two weeks were reserved for the rocket launches, and a review lecture on technical report writing. The grading for the module (which was normally $1 / 3$ of the course grade) was based on a score evaluated as follows:

$$
\begin{aligned}
\text { SCORE }= & {[\text { Preflight Inspection }]+[\text { Launch Factor }]+[\text { Altitude Factor }] } \\
& +[\text { Time Factor }]+[\text { Post flight Inspection }]+[\text { Technical Report }]
\end{aligned}
$$

where each item was evaluated as follows:

Preflight Inspection: Done by the company's chief engineer after construction, and no later than the day before launch. The rocket's workmanship and any innovative design concepts will be evaluated on a scale of 0 to 15 points. Late preflight inspection will result in a significant reduction in score.

Launch Factor: A successful launch earns 10 points.

Altitude Factor: [Your altitude/Maximum altitude achieved among all rockets tested] x 5. Maximum of 5 points for this aspect of performance.

Time Factor: [Minimum time among all rockets tested/Your time] x 5. Time of flight will earn a maximum of 5 points. A rocket that is lost or cannot safely be recovered will be given a score of zero for the time factor.

Post flight Inspection: Done by the chief engineer or one of his designated senior engineers immediately after flight. Any post flight damage will deduct points from a maximum of 5 points.

Technical Report: The final written report will be evaluated by the chief engineer or his designee and graded on a scale of 0 to 60 points.

\section{Analytical performance prediction}

As stated previously, the students are given a simplified lecture on rocket flight at a level they can understand and the nomenclature of the commercial rocket engines is explained to them. Although the rocket kit manufacturer allows a choice of seven different engines, the students are limited to the three engines summarized in Table 2. This keeps the flights to a reasonable height for the size of field and associated recovery area available to the University.

Proceedings of the 2002 American Society for Engineering Education Annual Conference \& Exposition

Copyright () 2002, American Society for Engineering Education 
Table 2. Rocket engine specifications

\begin{tabular}{|l|l|l|l|l|l|l|}
\hline $\begin{array}{l}\text { Engine } \\
\text { Type }\end{array}$ & $\begin{array}{l}\text { Total } \\
\text { Impulse } \\
(\mathrm{N}-\mathrm{s})\end{array}$ & $\begin{array}{l}\text { Average } \\
\text { Thrust } \\
(\mathrm{N})\end{array}$ & $\begin{array}{l}\text { Thrust } \\
\text { Duration } \\
(\mathrm{s})\end{array}$ & $\begin{array}{l}\text { Time } \\
\text { Delay } \\
(\mathrm{s})\end{array}$ & $\begin{array}{l}\text { Initial } \\
\text { Mass } \\
(\mathrm{gm})\end{array}$ & $\begin{array}{l}\text { Propellant } \\
\text { Mass } \\
(\mathrm{gm})\end{array}$ \\
\hline $1 / 2 \mathrm{~A} 6-2$ & 1.25 & 6.23 & 0.2 & 2 & 15.0 & 1.56 \\
\hline A8-3 & 2.50 & 7.79 & 0.32 & 3 & 16.2 & 3.12 \\
\hline B4-4 & 5.00 & 4.15 & 1.1 & 4 & 21.0 & 8.33 \\
\hline
\end{tabular}

In the engine type designations, for example A8-3, the letter denotes the total impulse produced by the engine: $1 / 2 \mathrm{~A}$ engines produce an impulse between 0.626 and $1.25 \mathrm{~N}-\mathrm{s}$, A engines produce between 1.26 and $2.50 \mathrm{~N}-\mathrm{s}$, and $\mathrm{B}$ engines produce between 2.51 and $5.0 \mathrm{~N}$-s. The number following the impulse code letter, 8 in this example, specifies the motor's average thrust rounded off to the nearest newton. The last number, -3 , gives the burn time of the delay charge before parachute ejection, rounded off to the nearest second. In the lectures, the effect of motor impulse and average thrust on altitude reached by the rocket is described to the students in qualitative terms.

A simplified lecture on fluid dynamic drag is then presented to the students, together with a wind tunnel demonstration showing how rocket drag coefficient is determined. Students are given a value of rocket drag coefficient based on frontal area of the body of the rocket from wind tunnel tests, but they are asked to measure the diameter of their rocket to calculate this frontal area. The students are then shown how to predict their rocket's maximum altitude and coast time to apogee using graphs available in Malewicki ${ }^{14}$ and duplicated for them in the handout laboratory manual ${ }^{15}$. It is explained to the students that many times an engineer needs to use working curves for some period of time before he understands the complete theory behind the curves, and this portion of the project gives a good example of this. Entering these graphs with lift-off mass (determined during preflight inspection), and the product of drag coefficient with frontal area $\left(\mathrm{C}_{\mathrm{D}} \mathrm{A}\right)$ in square $\mathrm{mm}$, one can predict the maximum apogee altitude reached by the rocket and determine the coast time from motor burnout to apogee. Similar altitude and coast time information, together with burnout velocity, is presented in a different form in Ref. 16.

For the descent phase of flight, the students are given a simplified derivation for terminal velocity where the downward acting weight force is balanced by the upward acting drag force. This results in the familiar equation

$$
\mathrm{V}_{\mathrm{T}}=\sqrt{ } 2 \mathrm{~W}_{\mathrm{BO}} / \rho \mathrm{C}_{\mathrm{DP}} \mathrm{A}
$$

where: $\quad \mathrm{V}_{\mathrm{T}}=$ terminal velocity $(\mathrm{m} / \mathrm{s})$

$$
\mathrm{W}_{\mathrm{BO}}=\text { Burnout weight }(\mathrm{N})
$$

Proceedings of the 2002 American Society for Engineering Education Annual Conference \& Exposition 


$$
\begin{array}{ll}
\rho & =\text { air density }\left(1.2 \mathrm{~kg} / \mathrm{m}^{3}\right) \\
\mathrm{C}_{\mathrm{DP}} & =\text { parachute drag coefficient }(1.3) \\
\mathrm{A}_{\mathrm{P}} & =\text { Flat planform area of parachute }\left(\mathrm{m}^{2}\right)
\end{array}
$$

The descent time can then be calculated from the fact that the rocket must descend from the same height it originally reached, $\mathrm{h}_{\max }$. Therefore,

$$
\mathrm{t}_{\text {desc }}=\mathrm{h}_{\max } / \mathrm{V}_{\mathrm{T}}
$$

The total predicted time of flight is then

$$
\mathrm{t}=\mathrm{t}_{\text {burn }}+\mathrm{t}_{\text {coast }}+\mathrm{t}_{\text {desc }}
$$

This time is then compared with the measured flight time from ignition to landing. The students are told that decreasing descent time means increasing terminal velocity, and the best way to do this is to modify the parachute in some way, the most obvious way being to reduce its projected area by reducing the diameter, or cutting holes or other kinds of openings into the parachute. Although this changes the drag coefficient somewhat due to changes in opened shape, at the freshman level, the assumption is made that the drag coefficient remains constant, and only the projected area changes. The students are cautioned not to increase terminal velocity too much, as this will cause damage to the rocket on impact and deduct from the post flight inspection score.

\section{Flight testing procedure}

The flight tests were conducted in laboratory sessions of two hours duration on the University athletic fields. Experience showed that approximately eight launches and recoveries could be conducted in a two-hour session. Winds were first measured with a hand held anemometer to insure they were below $9 \mathrm{~m} / \mathrm{s}$. Wind compensation requires tilting the launcher rod into the wind, but this decreases altitude and the accuracy of the altitude measurement, not to mention problems with wind drift causing loss of the model. Altitude is measured with an "altitracker," a large pistol-like sighting device that measures the angle of elevation at apogee, and allows calculation of altitude when combined with a ground-measured distance from the launch site. The student conducts a countdown and actuates a firing button that electrically ignites the propellant in the small commercial rocket motor. All other students are positioned a safe distance away, but which allows easy viewing of the entire flight. The instructor operates a stopwatch to measure the total time of flight from ignition to touchdown.

After touchdown, a post-flight inspection is conducted to assess for any damage to the rocket caused by an attempt to return the rocket to earth too quickly, or from poor design modifications. The student is assigned a post flight inspection score. Students are then given two weeks to write a final report outlining the entire project and comparing theoretical predictions of altitude and flight time with measured values. In the report, a section discussing reasons for differences is expected and students are expected to give this item considerable thought, as it is very relevant to the type of analytical predictions engineers learn to make.

Typical results Typical performance achieved by these rockets is summarized in Table 3 . The performance is categorized by engine type, since the engine selected most influences the altitude reached. The table lists average values over several years of launches, as well as values for maximum altitude achieved and minimum flight time achieved.

\section{Proceedings of the 2002 American Society for Engineering Education Annual Conference \& Exposition Copyright (C) 2002, American Society for Engineering Education}


Table 3. Rocket performance summary

\begin{tabular}{|c|c|c|c|c|c|c|}
\hline Engine & $\begin{array}{c}\text { Predicted } \\
\text { apogee } \\
\text { altitude } \\
(\mathrm{m})\end{array}$ & $\begin{array}{c}\text { Average } \\
\text { measured } \\
\text { altitude } \\
(\mathrm{m})\end{array}$ & $\begin{array}{c}\text { Maximum } \\
\text { measured } \\
\text { altitude } \\
(\mathrm{m})\end{array}$ & $\begin{array}{c}\text { Predicted } \\
\text { Flight } \\
\text { Time } \\
(\mathrm{s})\end{array}$ & $\begin{array}{c}\text { Average } \\
\text { Measured } \\
\text { Time } \\
(\mathrm{s})\end{array}$ & $\begin{array}{c}\text { Minimum } \\
\text { Measured } \\
\text { Time } \\
(\mathrm{s})\end{array}$ \\
\hline $1 / 2 \mathrm{~A} 6-2$ & 35 & 21 & 30 & 14.6 & 10.4 & 11.3 \\
\hline A8-3 & 81 & 61 & 104 & 31.4 & 22.3 & 34.2 \\
\hline B4-4 & 162 & 88 & 169 & 61.0 & 50.8 & 38.8 \\
\hline
\end{tabular}

Measurement accuracy For this type of introductory project, measurement accuracy is not critical. The time measurement was done with a standard stopwatch, so accuracy would be to a fraction of a second. Altitude was much more difficult to determine accurately because of wind drift and difficulty in keeping the altitude tracker pointed at the rocket. Operator accuracy in following the rocket in the sights and locking in the angle at maximum altitude was quite coarse. The angle indicator itself is only calibrated to the nearest two degrees. The horizontal distance over the ground between launch site and the altitude tracker was measured with a commercial rolling wheel (Rolatape) accurate to $8.3 \mathrm{~cm}$ per $100 \mathrm{~m}$ on hard ground. On grassy surfaces such as over the launch field, the accuracy would be less. For these reasons, the percentage of project points assigned to altitude and flight time was kept low enough so that measurement errors would not seriously prejudice a student's grade.

Differences between theory and experiment There are a large number of reasons why theory and experiment might differ in this project. The manufacturer of the rocket engines states that the ejection charge delay time is accurate to only one second, and that motor impulse is accurate to $+/$ - five percent. Also, the model construction finish achieved by most students was not as good a quality as the model rocket tested in the wind tunnel. However, it is expected that the main reason for the differences between theory and experiment was due to wind compensation requiring tilting the launch rail into the wind, thus lowering the actual altitude reached. The wind compensation was necessary to prevent the rockets from drifting beyond the confines of the fields available. More accurate results would be obtained by launching on a calm day, but the course schedule did not permit this. Student reports were examined to see what reasons they gave to account for these differences.

Clever modifications A number of clever modifications have been developed by students to achieve the desired objectives. One student gained a significant increase in altitude with a midsize engine by lowering the launch weight of the rocket by cutting off and discarding a portion of the rocket motor casing. The motor casing is made of a rolled cardboard, and for smaller motors that are not full of propellant, it is possible to saw off the upper portion of the motor casing without affecting safety. Students typically make parachute modifications to shorten the flight time by reducing the diameter of the parachute or cutting openings into it. Some students tie the suspension lines together in a reefing arrangement so that the parachute cannot open fully, thus lowering the projected frontal area in this manner. Another student shortened the flight time by attaching $15.2 \mathrm{~m}$ of fine monofilament fishing line between the rocket body and the parachute. The effect was that, at parachute ejection, the rocket freely dropped the $15.2 \mathrm{~m}$ while the

Proceedings of the 2002 American Society for Engineering Education Annual Conference \& Exposition Copyright $\odot$ 2002, American Society for Engineering Education 
parachute was opening, and all during the descent the rocket was hanging $15.2 \mathrm{~m}$ lower than the parachute. Since timing of flight time is stopped when the rocket body hits the ground (parachute still $15.2 \mathrm{~m}$ in the air), the student was able to shave a few seconds off his total flight time.

Another clever innovation used by one student was the use of a transparent film parachute instead of the customary orange and white mylar parachute provided in the kit, and the dispersal of a load of metallic foil particles during parachute ejection. The clear parachute was to prevent visual detection by the "enemy", and the dispersal of the chaff was to confuse the enemy radar stations. While neither of these modifications changed the altitude or flight time of the rocket, it showed that the student was doing some good thinking, and gained a few extra points during the preflight inspection.

\section{Student Evaluations of the Course}

Each year that this Introduction to Engineering course has been offered, student evaluations have been conducted. After two years of experience, a thermodynamics module was dropped from the course partly because of student response. The students felt they were simply "plugging" numbers into a computer program without understanding what was going on. The comments on the other three modules (manufacturing, mechanism design, and rocketry) were generally favorable, and these other three modules have been continued to the present. The author and his department ${ }^{17}$ have available detailed evaluations, both qualitative and quantitative, of the course as a whole, and of the individual modules.

Annual reviews of these evaluations have shown that the remaining three modules are all serving their function of introducing freshmen to topics in the engineering profession in an effective manner. It is not the purpose of this paper to comment on the value of each module, but merely to point out that the students generally found the rocketry module the most interesting and motivational. This is the type of project that freshmen students need, to maintain their interest in engineering.

Other Applications This project could also be used as a laboratory experiment in physics, dynamics, or fluid mechanics. In such a case, the experiment would have to be controlled better, especially the measurement of altitude. The lectures would be tailored so that the experiment illustrated the particular topic being covered in the course. For example, in a freshman physics course, the experiment could be conducted much as it was here in the Introduction to Engineering course. It would be given in sequence after the physics course covered the topics of impulse and momentum, and fluid dynamic drag. In a dynamics course, a brief summary of fluid dynamic drag could be given in an elementary form, as it was in this project, and then the experiment could be conducted after coverage of impulse and momentum. In a fluid mechanics course, the project could be given after the topic of fluid dynamic drag was covered, with only a brief outline of the project, and no new theory being given.

\section{Conclusions}

Model rocketry is an effective way to introduce students to aerospace engineering, and also a good way to maintain freshman student interest in an engineering program and encourage them

Proceedings of the 2002 American Society for Engineering Education Annual Conference \& Exposition Copyright ( 2002, American Society for Engineering Education 
to continue in their engineering studies. Five years of experience at the University of Massachusetts Lowell, including numerous student evaluations, have shown this to be the case. It is recommended that other schools try this approach, especially in the freshman year, and evaluate the results for themselves.

\section{References}

1. Budny, Dan, William LeBold, and Goranka Bjedov, "Assessment of the Impact of Freshman Engineering Courses," Journal of Engineering Education, v. 87, no. 4, October 1998, pp. 405-411.

2. Porter, Richard L., and Hugh Fuller, “A New 'Contact-Based' First Year Engineering Course," Journal of Engineering Education, v. 87, no. 4, October 1998, pp. 399-404.

3. Webster, Thomas J., and Kay C. Dee, "Supplemental Instruction Integrated Into an Introductory Engineering Course," Journal of Engineering Education, v. 87, no. 4, October 1998, pp. 377-383.

4. Petroski, Henry, "Polishing the Gem: A First-Year Design Project," Journal of Engineering Education, v. 87, no.

4, October 1998, pp. 445-448.

5. Little, Patrick, and Mary Cardenas, "Use of "Studio" Methods in the Introductory Engineering Design

Curriculum," Journal of Engineering Education, v. 90, no. 3, July 2001, pp. 309-318.

6. Sorby, Sheryl A., and Beverly J. Baartmans, "The Development and Assessment of a Course for Enhancing the 3-D Spatial Visualization Skills of First Year Engineering Students," Journal of Engineering Education, v. 89, no. 3, July 2000, pp. 301-307.

7. Fournier-Bonilla, Sheila D., Karan L. Watson, and Cesar Malave, "Quality Planning in Engineering Education: Analysis of Alternative Implementations of a New First-Year Curriculum at Texas A \& M University," Journal of Engineering Education, v. 89, no. 3, July 2000, pp. 315-322.

8. Pendergrass, N.A., Robert E. Kowalczyk, John P. Dowd, Raymond N. Laoulache, William Nelles, James A. Golen, and Emily Fowler, "Improving First-Year Engineering Education," Journal of Engineering Education, v. 90, no. 1, January 2001, pp. 33-41.

9. Stengel, Robert F., "From the Earth to the Moon: A Freshman Seminar," Journal of Engineering Education, v. 90, no. 2, April 2001, pp. 173-178.

10. Newman, Dava J., and Amir R Amir, "Innovative First Year Aerospace Design Course at MIT," Journal of Engineering Education, v. 90, no. 3, July 2001, pp. 375-381.

11. Higley, K. A., and C. M. Marianno, "Making Engineering Education Fun," Journal of Engineering Education, v. 90, no. 1, January 2001, pp. 105-107.

12. Yokomoto, Charles F., Maher E. Rizkalla, Carol L. O'Loughlin, Mohamed A. El-Sharkawy, and Nancy P. Lamm, "Developing a Motivational Freshman Course Using the Principle of Attached Learning," Journal of Engineering Education, v. 88, no. 1, January 1999, pp. 99-106.

13. Courter, Sandra Shaw, Susan B. Millar, and Lyman Lyons, "From the Student's Point of View: Experiences in a Freshman Engineering Design Course," Journal of Engineering Education, v. 87, no. 3, July 1998, pp. 283-288.

14. Malewicki, "Model Rocket Altitude Performance," Technical Information Report 100, Centuri Engineerin g Co., Phoenix, AZ, 1970.

15. Niemi, E.E., Jr., "Rocket Design Project Laboratory Manual, 25.108 Introduction to Engineering II," Mechanical Engineering Dept., University of Massachusetts Lowell, Lowell, MA, Spring 2001.

16. Anon., "Model Rocket Altitude Prediction Charts," Model Rocket Technical Report TR-10, Estes Industries, Penrose, CO, 1971.

17. http://m-5.uml.edu or Eugene_Niemi@uml.edu 


\section{Biography \\ EUGENE E. NIEMI, JR.}

Eugene Niemi is Professor of Mechanical Engineering at the University of Massachusetts Lowell, where he teaches courses in aerodynamics, fluid mechanics, and heat transfer. He received a BS degree in aeronautical engineering from Boston University and a PhD from the University of Massachusetts Amherst. Prior to teaching, he worked at General Electric and for Raytheon Company Missile Systems Division on surface-to-air, air-to-air, and small ballistic missiles. He has been a Summer Faculty Fellow at NASA and AEDC, and a member of AIAA and ASME. 